\title{
Long-Term Prognosis in Young Patients with Acute Coronary Syndrome Treated with Percutaneous Coronary Intervention
}

\author{
Oren Yagel* \\ Naseem Shadafny* \\ Ran Eliaz \\ Gil Dagan \\ David Leibowitz \\ Ilgar Tahiroglu \\ David Planer \\ Offer Amir \\ Gabby Elbaz Greener (D* \\ Ronny Alcalai* \\ Department of Cardiology, Hadassah \\ Medical Center, Jerusalem, Israel; Faculty \\ of Medicine, Hebrew University of \\ Jerusalem, Jerusalem, Israel \\ *These authors contributed equally to \\ this work
}

Correspondence: Gabby Elbaz Greener Hadassah Medical Center, Cardiology Division, Room Number I 14, Jerusalem, Israel

Tel +972(2)6776564

Fax +972(2)64II 028

Email Gabby@hadassah.org.il
Background: Acute coronary syndrome (ACS) at a young age is uncommon. Limited data regarding the long-term follow-up and prognosis in this population are available. Our objectives were to evaluate the long-term clinical outcomes of patients presenting with ACS at a young age and to assess factors that predict long-term prognosis.

Methods: A retrospective analysis of consecutive young patients (male below 40 and female below 50 years old) that were admitted with ACS and underwent percutaneous coronary intervention (PCI) between the years 1997 and 2009. Demographics, clinical characteristics, and clinical outcomes including major cardiovascular (CV) events and mortality were analyzed. Multivariable cox proportional hazard model was performed to identify predictors of long-term prognosis.

Results: One-hundred sixty-five patients were included with a mean follow-up of $9.1 \pm 4.6$ years. Most patients were men (88\%), and mean age (years) was $36.8 \pm 4.2$. During follow-up, $15(9.1 \%)$ died, 98 (59.4\%) patients had at least one major CV event, 22 (13.3\%) patients had more than two $\mathrm{CV}$ events, and the mean number of recurrent $\mathrm{CV}$ events was $1.4 \pm 1.48$ events per patient. In multivariate analysis, the strongest predictors of major CV events and/or mortality were coronary intervention without stent insertion (HR1.77; 95\% CI 1.09-2.9), LAD artery involvement (HR 1.59; 95\% CI 1.04-2.44) and hypertension (HR 1.6; 95\% CI 1.0-2.6).

Conclusion: Patients with ACS in young age are at high risk for major CV and/or mortality in long-term follow-up with a high rate of recurrent CV events. Close follow-up and risk factor management for secondary prevention have a major role, particularly in this population.

Keywords: acute coronary syndrome, ACS, NSTEMI, STEMI, young population, outcomes

\section{Introduction}

Coronary artery disease (CAD) is a leading cause of morbidity and mortality worldwide. ${ }^{1,2}$ Several studies have shown that coronary atherosclerosis begins in the second or third decade of life with an increased prevalence with age in both males and females. ${ }^{3-5}$ However, the clinical manifestations of acute coronary syndrome (ACS) in most cases occur later, during the fifth to seventh decade of life ${ }^{6,7}$ and only $2-10 \%$ of all patients with ACS, are younger than 40 years old. ${ }^{8,9}$

Young patients with ACS have unique characteristics with distinct risk factors and clinical manifestations. Prior studies have shown that family history, hypercholesterolemia, sedentary lifestyles, obesity and smoking were common risk factors 
in young patients with ACS compared to older age groups. ${ }^{8,10-15}$ Diabetes and smoking in young patients is a significant risk factor for recurrent coronary events and interventions, as well as mortality. ${ }^{14,15}$ In addition, there is an association between ethnicity and geographical location and the incidence of ACS events at a young age. ${ }^{16,17}$

When compared to an older population, ST-segment elevation myocardial infarction (STEMI) is more common in young patients compared to non-ST-segment elevation myocardial infraction (NSTEMI). ${ }^{12,13,18}$ Young ACS patients have a lower incidence of multi-vessel (MVD) and left main (LM) disease, ${ }^{16,17}$ whereas involvement of the left anterior descending (LAD) artery is more common. $^{14}$

Previous studies in this population mainly focused on risk factors and the unique clinical characteristics of this group, ${ }^{11-18}$ while others focused on in-hospital and shortterm outcomes which demonstrated improved outcomes in the young ACS population. ${ }^{13,18,19}$ To date, only a limited number of studies have evaluated the long-term outcomes of this population, most of which were performed prior to the widespread use of the invasive strategy in patients with ACS. ${ }^{10,11,20}$ The goal of this study was to evaluate the long-term clinical outcomes of young patients with ACS who underwent percutaneous coronary intervention (PCI) and to elucidate predictive factors affecting long-term prognosis in this population.

\section{Methods}

A retrospective cohort study that was approved by the Institutional Research Ethics Board (IRB) at Hadassah Medical Center approval number 0685-17-HMO). The IRB approved that patients' consent was not required for this historical retrospective study that includes only deidentified data. Our study complied with the Declaration of Helsinki.

\section{Population and Data Collection}

We included consecutive patients that were admitted with a diagnosis of first ACS event in young age and underwent PCI at a tertiary medical center between the years 1997-2009. Young patients were defined as $\leq 40$ years for males, and $\leq 50$ years for females at the time of the presenting coronary event.

Demographic and clinical data were collected from the hospitals' electronic medical files system including hospitalization summary, cardiac catheterization and echocardiography reports as well as outpatient clinic reports.
Demographic variables included age, sex, and ethnic origin. Risk factors variables included hypertension (HTN), diabetes mellitus (DM), dyslipidemia, smoking and family history of ischemic heart disease (IHD) and clinical characteristics included ACS presentation type (unstable angina, NSTEMI, STEMI).

The angiographic and PCI data were retrieved from the procedural report and was reviewed by an expert interventional cardiologist. Procedural variables included location of culprit lesion, presence of MVD and PCI type (stent insertion vs plain old balloon angioplasty (POBA)).

\section{Outcome Variables}

Cardiovascular events were collected from the hospital database and from the patient's own medical files. Mortality was determined from hospital chart review and by matching identification numbers of patients with the Israeli National Population Register.

The clinical outcomes were defined as mortality and major CV event that included hospitalization for the following events: myocardial infarction (MI), cerebrovascular accident (CVA), percutaneous coronary intervention (PCI), coronary artery bypass graft surgery (CABG) and exacerbation of congestive heart failure (CHF).

\section{Statistical Analysis}

Differences in baseline characteristics were compared using unpaired $t$-test for continuous variables, $\chi 2$-distribution or Fisher's exact test for categorical variables. Differences between the frequencies of the different events; mortality and major events according to baseline characteristics of population were compared using $\chi 2$-distribution or Fisher's as appropriate. The event rate over time was displayed using the Kaplan-Meier method, with comparison between groups by Log rank test.

To examine the association between baseline characteristics and outcome, a multivariable cox proportional hazard model was used. For the mortality analysis, we used the total cohort, 165 patients as we have reliable information about the mortality date in all patients with matching identification numbers of patients with the Israeli National Population Register. For time for first CV event analysis and for the number of recurrent events analysis, we excluded patients that were lost to complete long-term follow-up. The final analysis for $\mathrm{CV}$ events included a cohort of 145 patients. The association between baseline characteristics and the annual event rate was examined by multivariate linear regression. 
For all analyses, we used SAS software version 9.4 (SAS Institute Inc., Cary, NC). A p $<0.05$ was considered statistically significant.

\section{Results}

A total of 165 patients who had ACS and PCI at a young age were included in the study. The mean follow-up was 9.1 \pm 4.6 years and median follow-up was 10 years (IQR: $5.67,10.75)$. The baseline and clinical characteristics of the study population are summarized in Table 1. Most of the patients (88\%) were males and $95 \%$ of the patients had at least one risk factor, the most common risk factor in our population was smoking.

Nearly half of the patients (48\%) presented with STsegment elevation myocardial infraction (STEMI) and 52\% non -STE-ACS. Surprisingly, the proportion of unstable angina was greater than that of NSTEMI (33\% vs $19 \%$, respectively); this may be dependent on the definition of UAP/MI that was not based on the high-sensitive troponin assays which were not available at the years of the study. The most common vessel involved was the LAD (44.2\%), while $42 \%$ had multi-vessel coronary disease (MVD). Most patients had good left ventricular function (Table 1).

\section{MACCE and Mortality Analysis}

Fifteen $(9.1 \%)$ patients died during follow-up while 98 (59.4\%) patients had at least one major CV event and 107 (64.9\%) patients had at least one major CV event and/or mortality (Figure 1). Hypertension, family history of ischemic heart disease and PCI without stent insertion were found to be predictors for major $\mathrm{CV}$ and/or mortality in the univariate analysis (Table 2). Survival curves of hypertensive versus non-hypertensive patients are presented in Figure 2.

In the multivariate regression analysis, the strongest predictors for MACCE and/or mortality were coronary intervention without stent insertion, LAD artery involvement and hypertension (Table 3).

\section{Recurrent Event Analysis}

The recurrent event analysis was performed for 145 patients with complete follow-up at the end of study follow-up (1/ 2018). Twenty-two patients (13.3\%) had three or more events during follow-up, the mean number of events was 1.4 \pm 1.48 per patient and the mean event rate per patient per year was $0.3 \pm 0.8$. The median number of events per patients was 1 (IQR 0.2) and the median event rate per patient per year was 0.14 (IQR: 0, 0.27). Recurrent events according to baseline characteristics are presented in Appendix Table 1.
Table I Baseline Characteristics

\begin{tabular}{|c|c|}
\hline Variable & $N=165$ \\
\hline Age (years) mean \pm SD & $36.81 \pm 4.24$ \\
\hline Male sex, n (\%) & $145(88)$ \\
\hline \multicolumn{2}{|l|}{ Origin, n (\%) } \\
\hline Arabs & $83(50)$ \\
\hline Jews & $82(50)$ \\
\hline \multicolumn{2}{|l|}{ Risk factors, n (\%) } \\
\hline Family history of IHD & $76(46)$ \\
\hline Hypertension & $33(20)$ \\
\hline Hyperlipidemia & $94(57)$ \\
\hline Diabetes mellitus & $25(15)$ \\
\hline Smoking & $110(67)$ \\
\hline \multicolumn{2}{|l|}{ ACS presentation, $\mathbf{n}(\%)$} \\
\hline Unstable angina & $54(33)$ \\
\hline NSTEMI & $31(19)$ \\
\hline STEMI & $80(48)$ \\
\hline \multicolumn{2}{|l|}{$\begin{array}{l}\text { LV function }{ }^{\text {a }} \text { (assessed by echocardiogram), } \\
\text { n (\%) }\end{array}$} \\
\hline Normal & $49(46.5)$ \\
\hline Mild to moderately reduced & $47(45)$ \\
\hline Severely reduced & $9(8.5)$ \\
\hline MVD & $70(42)$ \\
\hline \multicolumn{2}{|l|}{ Culprit lesion (\%) } \\
\hline LM & I (0.6) \\
\hline LAD & $73(44)$ \\
\hline LCX & $27(16)$ \\
\hline $\mathrm{RCA}$ & $47(29)$ \\
\hline Indeterminate & $17(28)$ \\
\hline $\mathbf{P C I} \geq \mathbf{I}$ stent & $130(82)$ \\
\hline
\end{tabular}

Note: ${ }^{\text {a }} 05$ Patients with available data.

Abbreviations: ACS, acute coronary syndrome; IHD, ischemic heart disease; IQR, interquartile; NSTEMI, non-ST elevation segment myocardial Infraction; STEMI, ST elevation segment myocardial Infraction; LV, left ventricle; LAD, left anterior descending; LCX, left circumflex; LM, left main; MVD, multi-vessel disease; PCI, percutaneous coronary intervention; RCA, right coronary artery.

In a linear multivariate regression model, the strongest predictor for recurrent event was hypertension (Table 4).

\section{Discussion}

We present an analysis of 165 young patients with ACS who underwent PCI at a young age, with a long-term mean follow-up of $9.1 \pm 4.6$ years. The main finding of this study is the remarkably high rate of recurrent $\mathrm{CV}$ events in the years following initial ACS. During follow-up, approximately $65 \%$ of the patients had at least one endpoint of 


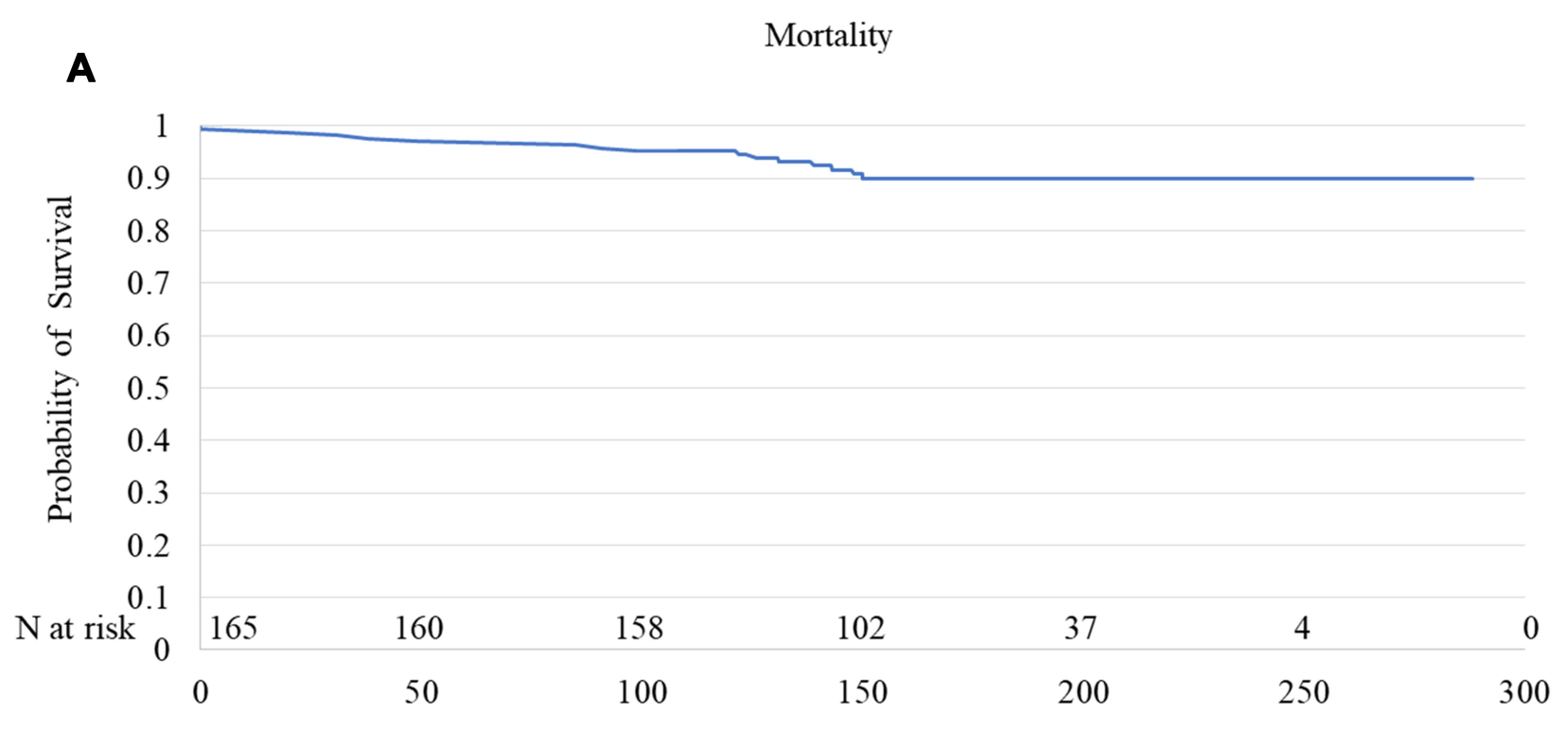

Follow-up time (months)

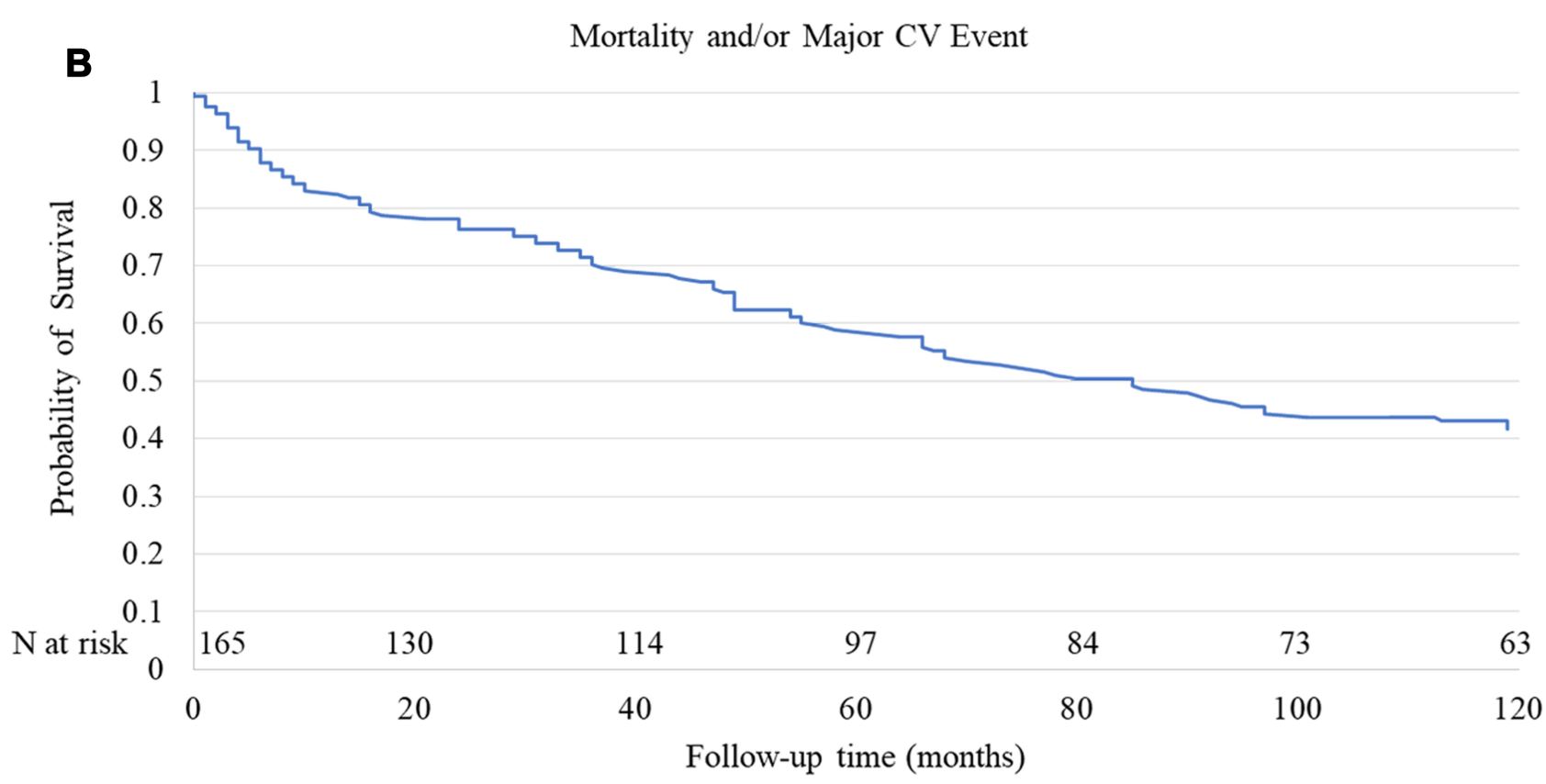

Figure I Kaplan-Meier survival curve showing cumulative survival free from mortality event (A) and from mortality and/or major CV event (B).

mortality or major $\mathrm{CV}$ event. The average number of recurrent events per patient was 1.85 , with an event rate of 0.3 per patient per year. These percentages are higher than previously published studies, in which the percentage of recurrent events was less than $30 \%{ }^{21}$ Moreover, in a more recent study with shorter follow-up of 3-5 years, only $11.2 \%$ patients younger than 45 years old had recurrent events with mortality rate of only $0.9 \%{ }^{14}$
The longer follow-up in our study and better recoding of events may explain the differences between our findings and prior studies. Another possible explanation is that our population may have lower compliance to optimal medical treatments and lifestyle modifications and thus a relatively high recurrent event rate.

It may be expected that in a more contemporary revascularization era the prognosis of young ACS patients will 
Table 2 Predictors for Mortality and/or Major CV Events (Univariate Analysis)

\begin{tabular}{|l|c|l|}
\hline Parameter & Hazard Ratio (95\% CI) & P-value \\
\hline Sex & I.55 (0.8I-2.97) & 0.19 \\
\hline Race & I.26 (0.86-I.85) & 0.23 \\
\hline HTN & I.84 (I.18-2.85) & 0.007 \\
\hline DM & I.08 (0.65-I.80) & 0.76 \\
\hline Smoking & I.05 (0.70-I.57) & 0.83 \\
\hline Family history of IHD & $0.63(0.43-0.94)$ & 0.02 \\
\hline LAD lesion & $1.38(0.94-2.01)$ & 0.09 \\
\hline MVD & I.17 (0.79-I.72) & 0.42 \\
\hline Stent; none vs $\geq 1$ & $2.00(1.26-3.18)$ & 0.003 \\
\hline
\end{tabular}

Abbreviations: CV, cardiovascular; DM, diabetes mellitus; HLP, hyperlipidemia HTN, hypertension; LAD, left anterior descending; MVD, multi-vessel disease; STEMI, ST-segment elevation myocardial infraction.

be better. However, our results do not support this assumption. One explanation is that the invasive approach influences mainly the short-term outcome, up to 1 year but thereafter factors such as lifestyle and compliance are more dominant for long-term prognosis. Furthermore, an invasive approach may be harmful in patients with poor compliance due to late stent thrombosis. Young patients who experience coronary events may have trouble to adhere with medications and risk factors' management and thus are exposed to recurrent adverse events. ${ }^{22}$ Hypertension prevalence in the first event was found only in $20 \%$ of the patients. However, in patients who died during follow-up or experienced MACCE, the percentages were much higher. We found that patients with hypertension had significantly shorter time to recurrent event (Figure 2). We found that hypertension was the strongest risk factor for recurrent $\mathrm{CV}$ events. This may be because hypertension is a less controlled among young patients who in many cases do not compliant with antihypertensive medications. ${ }^{22}$ We postulate that early intervention focusing on treatment of hypertension may reduce the risk for recurrent events.

Another finding in this study was that PCI without stent insertion was found to be an independent predictive factor for worse outcomes. Possible explanation may be the fact that patients who had complex or diffuse ectatic disease not suitable for stent implantation, have worse prognosis. ${ }^{23}$

Our study indicates that patients who had a coronary event at a young age are in a remarkably high risk for recurrent event during long-term follow-up. While the shortterm prognosis of these young patients is relatively good as they have less comorbidities, the long-term prognosis might be unfavorable. It seems that health systems should put more focus on the population of young ACS patients in order to improve compliance and potentially, prognosis.

The present study has several limitations. First, the study based on a retrospective administrative database that contains discharge-level records and as such is susceptible to reporting errors and missing data. In order to minimize those errors, we have crosschecked our data in several major databases and we believe that we were able to obtain high-quality long-term data which allowed a consistent analysis. Another limitation is the lack of a control group of older patients, these data were not

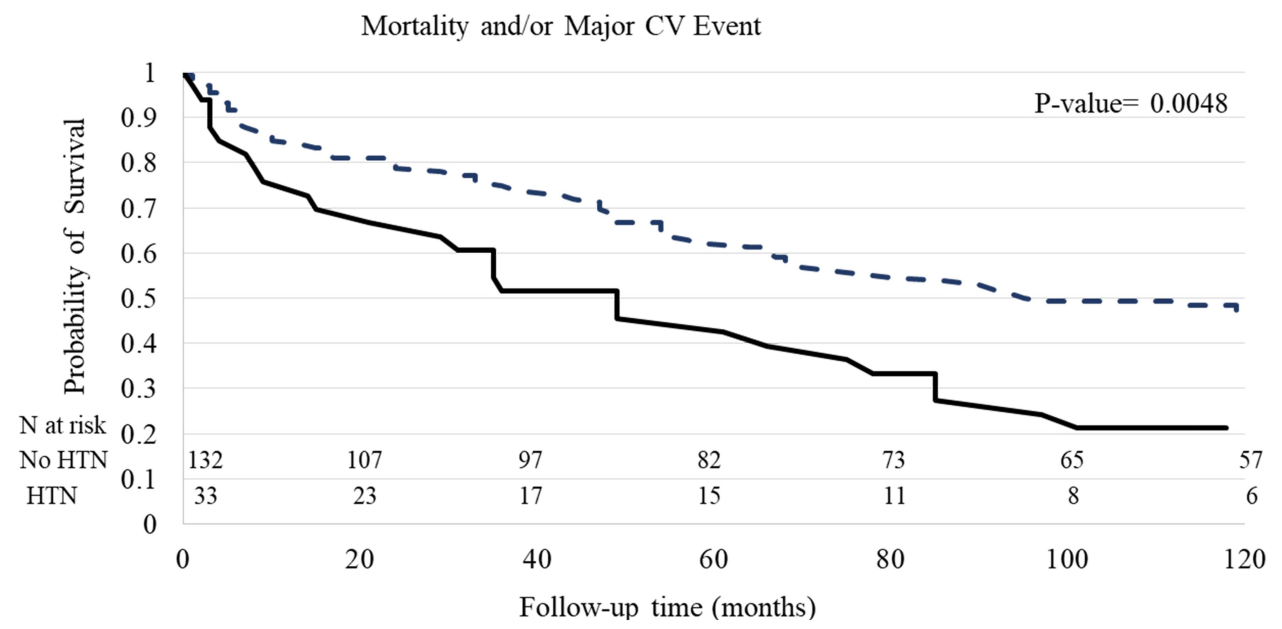

Figure 2 Kaplan-Meier survival curve showing cumulative survival free from mortality and major CV event in patient with and without hypertension. 
Table 3 Multivariable Cox Proportional Hazard Model for Major CV Event and/or Mortality

\begin{tabular}{|l|l|l|}
\hline Parameter & Hazard Ratio $\mathbf{( 9 5 \% ~ C l )}$ & P-value \\
\hline Sex & $1.18(0.57-2.42)$ & 0.65 \\
\hline Race & $1.13(0.74-1.73)$ & 0.58 \\
\hline HTN & $1.61(1.0-2.6)$ & 0.05 \\
\hline DM & $0.75(0.44-1.30)$ & 0.31 \\
\hline Smoking & $0.77(0.49-1.23)$ & 0.27 \\
\hline Family history of IHD & $0.67(0.45-1.02)$ & 0.06 \\
\hline LAD lesion & $1.59(1.04-2.44)$ & 0.03 \\
\hline MVD & $1.26(0.83-1.91)$ & 0.28 \\
\hline Stent; none vs $\geq 1$ & $1.77(1.09-2.9)$ & 0.02 \\
\hline
\end{tabular}

Abbreviations: CC, cardiovascular; DM, diabetes mellitus; HTN, hypertension; IHD, ischemic heart disease; LAD, left anterior descending; MVD, multi-vessel disease.

Table 4 Linear Model for Recurrent Annual Event $(\mathrm{N}=\mid 45)$

\begin{tabular}{|l|c|c|l|}
\hline Variable & Parameter & $\begin{array}{c}\text { Standard } \\
\text { Error }\end{array}$ & P-value \\
\hline Sex & -0.090 & 0.14 & 0.51 \\
\hline Race & -0.043 & 0.09 & 0.62 \\
\hline HTN & 0.310 & 0.11 & 0.004 \\
\hline DM & 0.062 & 0.12 & 0.59 \\
\hline Family history of IHD & -0.144 & 0.08 & 0.09 \\
\hline Smoking & -0.028 & 0.10 & 0.77 \\
\hline LAD involvement & 0.072 & 0.09 & 0.41 \\
\hline Stent insertion $\geq 1$ & 0.038 & 0.10 & 0.72 \\
\hline
\end{tabular}

Abbreviations: DM, diabetes mellitus; HTN, hypertension; IHD, ischemic heart disease; LAD, left anterior descending.

available in this cohort. However, data on the expected outcome of general ACS populations both old and young are abundant and we used it for reference as discussed.

In conclusion, the rate of mortality and recurrent $\mathrm{CV}$ events in patients who presented with ACS at a young age is relatively high during long-term follow-up. Hypertension, LAD disease and coronary intervention without stenting are important negative prognostic factors in this population. Early interventions to reduce risk factors and to improve compliance, particularly for hypertensive patients may lead to a better prognosis in this unique population.

\section{Acknowledgments}

The corresponding author affirms that he has listed everyone who contributed significantly to the work. The corresponding author had access to all the study data, take responsibility for the accuracy of the analysis, and had authority over manuscript preparation and the decision to submit the manuscript for publication. The corresponding author confirms that all authors read and approve the manuscript.

\section{Disclosures}

Dr David Leibowitz report grants, personal fees from Pfizer, outside the submitted work. The authors report no other conflicts of interest in this work.

\section{References}

1. Regmi M, Siccardi MA. Coronary artery disease prevention. Statpearls Treasure Island (Fl); 2020.

2. Nowbar AN, Gitto M, Howard JP, Francis DP, Al-Lamee R. Mortality from ischemic heart disease. Circ Cardiovasc Qual Outcomes. 2019;12: e005375. doi:10.1161/CIRCOUTCOMES.118.005375

3. Enos WF, Holmes RH, Beyer J. Coronary disease among United States soldiers killed in action in Korea; preliminary report. $J$ Am Med Assoc. 1953;152:1090-1093. doi:10.1001/jama.1953.03690120006002

4. McNamara JJ, Molot MA, Stremple JF, Cutting RT. Coronary artery disease in combat casualties in Vietnam. JAMA. 1971;216:1185-1187. doi:10.1001/jama.1971.03180330061012

5. Sanchis-Gomar F, Perez-Quilis C, Leischik R, Lucia A. Epidemiology of coronary heart disease and acute coronary syndrome. Ann Transl Med. 2016;4:256. doi:10.21037/ atm.2016.06.33

6. Behar S, Battler A, Porath A, et al., Internal Medicine S. A prospective national survey of management and clinical outcome of acute myocardial infarction in Israel, 2000. Isr Med Assoc J. 2003;5:249-254.

7. Arciero TJ, Jacobsen SJ, Reeder GS, et al. Temporal trends in the incidence of coronary disease. Am J Med. 2004;117:228-233. doi:10.1016/j.amjmed.2004.04.008

8. Choudhury L, Marsh JD. Myocardial infarction in young patients. Am J Med. 1999;107:254-261. doi:10.1016/S0002-9343(99)00218-1

9. Doughty M, Mehta R, Bruckman D, et al. Acute myocardial infarction in the young-The University of Michigan experience. Am Heart J. 2002;143:56-62. doi:10.1067/mhj.2002.120300

10. Yusuf S, Hawken S, Ounpuu S, et al.; Investigators IS. Effect of potentially modifiable risk factors associated with myocardial infarction in 52 countries (the INTERHEART study): case-control study. Lancet. 2004;364:937-952. doi:10.1016/S0140-6736(04)17018-9

11. Navas-Nacher EL, Colangelo L, Beam C, Greenland P. Risk factors for coronary heart disease in men 18 to 39 years of age. Ann Intern Med. 2001;134:433-439. doi:10.7326/0003-4819-134-6-20010320000007

12. Schoenenberger AW, Radovanovic D, Stauffer JC, et al. Acute coronary syndromes in young patients: presentation, treatment and outcome. Int $J$ Cardiol. 2011;148:300-304. doi:10.1016/j. ijcard.2009.11.009

13. Puricel S, Lehner C, Oberhansli M, et al. Acute coronary syndrome in patients younger than 30 years-aetiologies, baseline characteristics and long-term clinical outcome. Swiss Med Wkly. 2013;143:w13816. doi:10.4414/smw.2013.13816 
14. Tini G, Proietti G, Casenghi M, et al. Long-term outcome of acute coronary syndromes in young patients. High Blood Press Cardiovasc Prev. 2017;24:77-84. doi:10.1007/s40292-017-0183-6

15. Esteban MR, Montero SM, Sanchez JJ, et al. Acute coronary syndrome in the young: clinical characteristics, risk factors and prognosis. Open Cardiovasc Med J. 2014;8:61-67. doi:10.2174/ 1874192401408010061

16. Wolfe MW, Vacek JL. Myocardial infarction in the young. Angiographic features and risk factor analysis of patients with myocardial infarction at or before the age of 35 years. Chest. 1988;94:926-930. doi:10.1378/chest.94.5.926

17. Rathod KS, Jones DA, Gallagher S, et al. Atypical risk factor profile and excellent long-term outcomes of young patients treated with primary percutaneous coronary intervention for ST-elevation myocardial infarction. Eur Heart J Acute Cardiovasc Care. 2016;5:23-32. doi:10.1177/2048872614567453

18. Al-Murayeh MA, Al-Masswary AA, Dardir MD, Moselhy MS, Youssef AA. Clinical presentation and short-term outcome of acute coronary syndrome in native young Saudi population. $J$ Saudi Heart Assoc. 2012;24:169-175. doi:10.1016/j. jsha.2012.03.001
19. Venkatason P, Zubairi YZ, Zaharan NL, et al. Characteristics and short-term outcomes of young women with acute myocardial infarction in Malaysia: a retrospective analysis from the Malaysian National Cardiovascular Database registry. BMJ Open. 2019;9: e030159. doi:10.1136/bmjopen-2019-030159

20. Cole JH, Miller JI 3rd, Sperling LS, Weintraub WS. Long-term follow-up of coronary artery disease presenting in young adults. J Am Coll Cardiol. 2003;41:521-528. doi:10.1016/S0735-1097(02) 02862-0

21. Zimmerman FH, Cameron A, Fisher LD, Ng G. Myocardial infarction in young adults: angiographic characterization, risk factors and prognosis (Coronary Artery Surgery Study Registry). J Am Coll Cardiol. 1995;26:654-661. doi:10.1016/0735-1097(95)00254-2

22. Zhang Y, Moran AE. Trends in the prevalence, awareness, treatment, and control of hypertension among young adults in the United States, 1999 to 2014. Hypertension. 2017;70:736-742. doi:10.1161/ HYPERTENSIONAHA.117.09801

23. Boles U, Wiklund U, David S, Ahmed K, Henein MY. Coronary artery ectasia carries a worse prognosis: a long-term follow-up study. Pol Arch Intern Med. 2019;129:833-835. doi:10.20452/pamw.14959

\section{Publish your work in this journal}

Vascular Health and Risk Management is an international, peerreviewed journal of therapeutics and risk management, focusing on concise rapid reporting of clinical studies on the processes involved in the maintenance of vascular health; the monitoring, prevention and treatment of vascular disease and its sequelae; and the involvement of metabolic disorders, particularly diabetes. This journal is indexed on PubMed Central and MedLine. The manuscript management system is completely online and includes a very quick and fair peerreview system, which is all easy to use. Visit http://www.dovepress. com/testimonials.php to read real quotes from published authors. 